\title{
Radiographically Recognizable? An Investigation into the Appearance of Osteomalacic Pseudofractures
}

\author{
Emma Jennings ${ }^{1}$, Jo Buckberry ${ }^{2}$ and Megan Brickley ${ }^{1}$
}

${ }^{I}$ Department of Anthropology, McMaster University, Hamilton, Ontario L8S 4L8, Canada

${ }^{2}$ Department of Archaeological and Forensic Sciences, University of Bradford, Bradford BD7 $I D P, U K$

KEY WORDS Osteomalacia; Pseudofractures; Looser Zones; Radiography

ABSTRACT Pseudofractures, lucent bands that occur due to a build-up of osteoid, are a key feature of osteomalacia. In paleopathology, pseudofractures are often marked by small, linear cracks in the cortex of the bone surrounded by irregular, bony spicule formation. Radiography can be used to help diagnose pseudofractures, both clinically and in paleopathology. A detailed understanding of the radiographic appearance of pseudofractures and their development is, therefore, necessary to aid a diagnosis of vitamin D deficiency. The present study examined the clinical literature to determine current ideas on the appearance of pseudofractures with the aim of applying this knowledge to paleopathology. A radiographic study of the characteristics of pseudofractures was performed on five individuals with clear skeletal features of osteomalacia from archaeological sites in Canada and the United Kingdom dating to the medieval period $\left(5^{\text {th }}\right.$ to $15^{\text {th }}$ centuries) and the $19^{\text {th }}$ century. Results show that the radiographic appearance of pseudofractures could potentially reveal information about the cause of the deficiency and the chronicity of pseudofractures. This type of information has the potential to further our understanding of the lived experiences of archaeological individuals with osteomalacia.

\subsection{Introduction}

Osteomalacia is a type of metabolic bone disease resulting from vitamin D deficiency. The term is used to describe inadequate mineralisation of osteoid seams during normal bone turnover (Shore and Poznansky, 1999), so it is found in both juveniles and adults (Brickley and Ives, 2008). Clinically, the term 'rickets' is reserved for defects in endochondral mineralisation and so is limited to individuals who have not undergone physeal closure (Shore and Poznansky, 1999). Osteomalacia in juveniles is rarely specifically discussed in the paleopathological literature, despite the fact that such changes lead to the development of bowing deformities (Brickley and Ives, 2008). Vitamin D deficiency most commonly occurs due to nutritional causes, mainly a lack of exposure to sunlight in addition to minimal or no dietary supplementation. However, it can also have genetic or acquired causes (Brickley and Ives, 2008: Table 5.4).

Pseudofractures are a hallmark of osteomalacia. They first appear as lucent bands that can only be radiographically detected (Berry et al., 2002). Fractures then occur due to stresses on the poorly mineralized bone and appear as minor cracks in the cortex, which are visible macroscopically, and may eventually result in a complete fracture (Le May and Blunt, 1949). The bone is weakened owing to low blood serum levels of phosphorus and calcium, interrupting bone mineralization during remodeling and resulting in the accumulation of unmineralized osteoid (Mankin, 1974; Holick, 2007). Pseudofractures can occur at these weakened sites, and as 
fracture healing is impaired, healing may not advance until adequate levels of vitamin D, calcium, and phosphorus are restored (McKenna et al., 2004). Mineralization of the fracture callus occurs unevenly and to varying degrees of completeness, resulting in irregular, bony spicule formation (Bonucci et al., 1969). Previous clinical studies suggest that pseudofractures occur in individuals with severe osteomalacia (Magilligan and Dulligan, 1952; Chalmers et al., 1967; Habener and Mahaffey, 1978). These fractures can take around six months to fully develop and can be present for a number of years (Le May and Blunt, 1949; Chalmers et al., 1967; Berry et al., 2002). Pseudofractures have been reported in infants and older children (Keller and Barnes, 2008; Shore and Chesney, 2013), however, most clinical studies focus on pseudofractures in adults with osteomalacia.

It is important to note that there is a current debate in the clinical literature surrounding whether the term 'pseudofracture' is a suitable term for pathological osteomalacic lesions (McKenna et al., 1987; McKenna et al., 2014). These lesions have also been termed Looser's zones and, less commonly, Milkman's fractures, named after researchers who identified them, but all refer to the same pathological lesions. The term 'pseudofracture' has been kept in this paper as it is still commonly used in both clinical and paleopathological papers.

Pseudofractures can be subtle and are often easily overlooked in both clinical and paleopathological work (Aufranc et al., 1964; Reginato et al., 1999; Berry et al., 2002; McKenna et al., 2014). In paleopathology, this type of fracture offers a key means of suggesting a diagnosis of osteomalacia (Brickley and Ives, 2008; Ives and Brickley, 2014). The aim of this article is to evaluate the radiological features of pseudofractures and explore the biological underpinnings that may affect their appearance radiographically. In particular, consideration is given to how the cause of the deficiency, as well as the chronicity of the pseudofracture, can modify mineralisation and callus formation, which affect the pseudofracture's appearance on x-ray. This article also aims to evaluate how information from the radiological assessment of pseudofractures in paleopathology can contribute to our understanding of the lived experience of individuals with osteomalacia.

\subsection{Materials and Methods}

Five individuals with clear skeletal evidence of osteomalacia from England and Canada, dating from the Medieval period to the $19^{\text {th }}$ century, were investigated (Table 1). These five individuals were each found to have multiple, macroscopically visible pseudofractures. Pseudofractures were diagnosed based on characteristic features; multiple, symmetrical, small, and often incomplete fractures perpendicular to the bone cortex with irregular, bony spicule and woven bone callus formation found at key sites, such as the ribs, scapula, os coxae, clavicle, and femur (Ives and Brickley, 2014; Parfitt, 1998). Forty-six fractures were selected and radiographed and then assessed based on their appearance on x-ray. Radiographic literature describes pseudofractures as linear, radiolucent bands perpendicular to bone cortex (Berry et al., 2002; Brickley and Ives, 2008). Chronic pseudofractures have calluses that are typically thinner than non-pathological fractures, but tend to be denser and better defined, appearing as thin extracortical crescents of radiodensity (the term 'condensation' is sometimes used to describe 
these crescents, however, there is no clear definition for this term) (Edeiken and Schneeberg, 1943; Nowell et al., 1951; Berry et al., 2002).

Pseudofractures from St. Martin's, Birmingham, UK, have been previously reported (Brickley et al., 2006; Brickley et al., 2007). Three rib fragments with pseudofractures had been retained from reburial for histological analysis and were x-rayed as part of this study. The x-rays of the remaining pseudofractures, made at the time of the original investigation, were reevaluated.

Age and sex were assessed following standards outlined in Buikstra and Ubelaker (1994). Digital, industrial x-ray machines were used to obtain radiographs of each of the pseudofractures. Digital, industrial machines produce higher quality images than clinical radiographs. The images can be readily manipulated to improve brightness, contrast, and magnification, and are therefore suited to diagnosing lesions (Buckberry and O'Connor, 2007). Local settings for exposure and $\mathrm{kV}$ level were used based on the size and density of the skeletal element examined. Where possible, fracture lines, which usually occur perpendicular to the involved cortical bone, were oriented parallel to the $\mathrm{x}$-ray imaging plate.

\section{Table 1}

The collection, date, number of pseudofractures evaluated, and x-ray equipment used for each of the five individuals in this study.

\begin{tabular}{|c|c|c|c|c|c|}
\hline Individual & SMB 601 & SMB 135 & HK 32 & PAT 7A2 54 & PAT 7A2 57 \\
\hline Collection & $\begin{array}{l}\text { St. Martin's } \\
\text { Cemetery, } \\
\text { Birmingham, } \\
\text { UK }^{1}\end{array}$ & $\begin{array}{l}\text { St. Martin's } \\
\text { Cemetery, } \\
\text { Birmingham, } \\
\text { UK }^{1}\end{array}$ & $\begin{array}{l}\text { Hickleton, } \\
\text { South } \\
\text { Yorkshire, UK }{ }^{1}\end{array}$ & $\begin{array}{l}\text { Pointe-aux- } \\
\text { Trembles, } \\
\text { Montreal, } \\
\text { Canada }^{2}\end{array}$ & $\begin{array}{l}\text { Pointe-aux- } \\
\text { Trembles, } \\
\text { Montreal, } \\
\text { Canada }^{2}\end{array}$ \\
\hline Date & $\begin{array}{l}18^{\text {th }}-19^{\text {th }} \\
\text { century, urban }\end{array}$ & $\begin{array}{l}18^{\text {th }}-19^{\text {th }} \\
\text { century, urban }\end{array}$ & $\begin{array}{l}\text { Medieval to } \\
\text { post-medieval, } \\
\text { rural }\end{array}$ & $\begin{array}{l}18^{\text {th }}-19^{\text {th }} \\
\text { century, urban }\end{array}$ & $\begin{array}{l}18^{\text {th }}-19^{\text {th }} \\
\text { century, urban }\end{array}$ \\
\hline Age at Death & $\begin{array}{l}\text { Adult (exact age } \\
\text { undetermined) }\end{array}$ & $\begin{array}{l}\text { Adult (exact age } \\
\text { undetermined) }\end{array}$ & $\begin{array}{l}\text { Young Adult } \\
(20-34)\end{array}$ & Old Adult (50+) & $\begin{array}{l}\text { Young Adult } \\
(20-34)\end{array}$ \\
\hline Sex & Male & Female & Female & Probable Male & Probable Male \\
\hline $\begin{array}{l}\text { Number of } \\
\text { Pseudofractures }\end{array}$ & 14 & 4 & 17 & 7 & 4 \\
\hline $\begin{array}{l}\text { X-Ray } \\
\text { Equipment }\end{array}$ & $\begin{array}{l}\text { Golden } \\
\text { Engineering } \\
\text { XR200 source } \\
\text { and FlashX Pro } \\
\text { Digital Detector } \\
\text { Array, } \\
\text { McMaster } \\
\text { University / } \\
\text { Kodak } \\
\text { Industrex } \\
\text { Ready-pack } \\
\text { Mammogram } \\
\text { Film, English } \\
\text { Heritage Centre } \\
\text { for Archaeology }\end{array}$ & $\begin{array}{l}\text { Golden } \\
\text { Engineering } \\
\text { XR200 source } \\
\text { and FlashX Pro } \\
\text { Digital Detector } \\
\text { Array, } \\
\text { McMaster } \\
\text { University / } \\
\text { Kodak } \\
\text { Industrex } \\
\text { Ready-pack } \\
\text { Mammogram } \\
\text { Film, English } \\
\text { Heritage Centre } \\
\text { for Archaeology }\end{array}$ & $\begin{array}{l}\text { Faxitron source } \\
\text { and Fujifilm } \\
\text { Dynamix HR2 } \\
\text { CR unit, } \\
\text { University of } \\
\text { Bradford }\end{array}$ & $\begin{array}{l}\text { Golden } \\
\text { Engineering } \\
\text { XR200 source } \\
\text { and FlashX Pro } \\
\text { Digital Detector } \\
\text { Array, } \\
\text { University of } \\
\text { Montreal }\end{array}$ & $\begin{array}{l}\text { Golden } \\
\text { Engineering } \\
\text { XR200 source } \\
\text { and FlashX Pro } \\
\text { Digital Detector } \\
\text { Array, } \\
\text { University of } \\
\text { Montreal }\end{array}$ \\
\hline
\end{tabular}




\begin{tabular}{|c|c|c|c|c|c|}
\hline $\mathrm{kV}$ & Ribs: $50-55 \mathrm{kV}$ & $\begin{array}{l}\text { Rib: } 50 \mathrm{kV} \\
\text { Scapula, } \\
\text { clavicle: } 65 \mathrm{kV}\end{array}$ & $\begin{array}{l}\text { Ribs: } 50 \mathrm{kV} \\
\text { Vertebra: } 70 \mathrm{kV} \\
\text { Os coxae, } \\
\text { scapula, } \\
\text { clavicle: } 90 \mathrm{kV}\end{array}$ & $\begin{array}{l}\text { Ribs: } 50 \mathrm{kV} \\
\text { Scapula: } 90 \mathrm{kV}\end{array}$ & Ribs: $50 \mathrm{kV}$ \\
\hline xposure Time & $10-18$ seconds & 10-18 seconds & 90 seconds & 10 seconds & 10 seconds \\
\hline
\end{tabular}

${ }^{1}$ Case of osteomalacia previously diagnosed based on macroscopic features diagnostic of the disease.

${ }^{2}$ Case of osteomalacia diagnosed during the course of this study based on macroscopic and radiographic features diagnostic of the disease.

\subsection{Results}

Forty-eight pseudofractures were identified macroscopically ranging from thin cracks in the bone cortex to those with substantial callus formation. Forty-one of the pseudofractures had callus formation that was visible macroscopically. Thirty of the calluses were visible radiographically, suggesting some of the calluses present were insufficiently mineralised and therefore not visible as sclerotic areas on the radiographs. The macroscopic appearance did not relate to the radiological appearance. The results are summarized in Table 2. As radiological procedures were controlled (see Section 1.2), it is likely that the amount of callus and its degree of mineralization had the greatest influence upon the appearance of a callus radiographically (see Section 1.4).

\section{Table 2}

The number of pseudofracture calluses visible on x-ray, arranged by individual and bone element.

\begin{tabular}{|c|c|c|c|c|c|c|c|}
\hline Individual & Site & Rib & Scapulae & Vertebrae & Os Coxae & Clavicle & $\begin{array}{l}\text { Total } \\
\text { pseudo- } \\
\text { fractures } \\
\text { with callus }\end{array}$ \\
\hline SMB 601 & $\begin{array}{l}\text { St. Martin's } \\
\text { Cemetery, } \\
\text { Birmingham }\end{array}$ & $7 / 14$ & --- & --- & --- & --- & $7 / 14$ \\
\hline SMB 135 & $\begin{array}{l}\text { St. Martin's } \\
\text { Cemetery, } \\
\text { Birmingham }\end{array}$ & $0 / 1$ & $2 / 2$ & --- & --- & $1 / 1$ & $3 / 4$ \\
\hline HK 32 & $\begin{array}{l}\text { Hickleton, } \\
\text { South } \\
\text { Yorkshire }\end{array}$ & $9 / 10$ & $3 / 4$ & $0 / 1$ & $0 / 3$ & $0 / 1$ & $12 / 19$ \\
\hline $\begin{array}{l}\text { PAT 7A2 } \\
54\end{array}$ & $\begin{array}{l}\text { Pointe-aux- } \\
\text { Trembles, } \\
\text { Montreal }\end{array}$ & $6 / 6$ & $0 / 1$ & --- & --- & --- & $6 / 7$ \\
\hline $\begin{array}{l}\text { PAT 7A2 } \\
57\end{array}$ & $\begin{array}{l}\text { Pointe-aux- } \\
\text { Trembles, } \\
\text { Montreal }\end{array}$ & $2 / 4$ & --- & --- & --- & --- & $2 / 4$ \\
\hline Total & & $24 / 35$ & $5 / 7$ & $0 / 1$ & $0 / 3$ & $1 / 2$ & $30 / 48$ \\
\hline
\end{tabular}




\subsection{Discussion}

There has been recent criticism that the biological underpinnings of lesions need to be explored in paleopathological research (Mays, 2018). Therefore, this section considers the bone mechanics that affect callus formation and degree of mineralisation in pseudofractures, which will influence whether a callus is visible radiographically. Examination of the clinical literature reveals that these factors may relate to the underlying cause of the deficiency and/or the chronicity of the pseudofractures under study, and are discussed below. Finally, cause of deficiency and chronicity are considered in the pseudofractures investigated here with the aim of understanding the lived experience of individuals with osteomalacia.

\section{Cause of vitamin D deficiency}

Without adequate vitamin D, only $10 \%$ to $15 \%$ of dietary calcium and $60 \%$ of phosphorus are absorbed, leading to diminished mineralization and increasing the risk of fracture (Holick, 2007). Studies of the structure of osteomalacic bone suggest that less osteoid is mineralized as osteomalacia advances, with no osteoid mineralization occurring in the most advanced cases (Parfitt, 2005). In nutritional deficiencies, the amount of osteoid relative to bone has been found to be between two and ten percent, with severity fluctuating seasonally as vitamin D is intermittently obtained from exposure of the skin to sunlight at times that would permit its synthesis (Priemel et al., 2010). One histological study that specifically looked at individuals with nutritional deficiencies found that advanced bone formation can occur, although it does so irregularly and slowly (Bonucci et al., 1969). Patients in the Bonucci (1969) study all presented with pseudofractures and the presence of woven bone was identified. The pathophysiology associated with nutritional vitamin D deficiency is one of irregular, delayed mineralization, which fits with what is seen macroscopically in paleopathological cases of pseudofractures, and what is seen on the radiographs in this study and other clinical studies (see Fig. 1).

There is evidence that a lesser degree of mineralisation occurs in genetic cases of vitamin D deficiency, mainly from histological studies. For example, dentin mineralization occurs through similar processes to bone mineralization and is therefore equally susceptible to the effects of vitamin D deficiency. One study of interglobular dentin, which is present in cases of vitamin D deficiency when dentin fails to properly mineralize, showed that individuals with genetic deficiencies have more severely delayed and inhibited dentin mineralization, even after several decades (Foster et al., 2014). Similarly, a study conducted on mice revealed that less bone is mineralized in genetic cases when compared to nutritional osteomalacia (Faibish and Boskey, 2005). Finally, the amount of osteoid relative to bone in genetic forms of osteomalacia is over ten percent, compared to two to ten percent in nutritional cases (Parfitt, 2005). However, parsing apart the difference in the radiographic appearance of pseudofractures caused by nutritional versus inherited/acquired deficiencies in the modern radiographic literature is complicated by the fact that, with the exception of case studies, many studies do not separate out the cause of the deficiency (e.g. Çakur et al., 2012; Fogelman and Carr, 1980; Reginato et al., 1999).

It is important to note that while pseudofractures are frequently reported in clinical cases of osteomalacia, the development of calluses in pseudofractures are debated, particularly in the 
radiographic literature. As discussed above, there is histological evidence that mineralisation and advanced bone formation can occur in cases of nutritional deficiencies. However, radiological papers offer divergent opinions on whether callus are present on x-ray prior to treatment (see Table 3). It is possible that the presence of a callus on x-ray again results from the cause of the deficiency or its severity. The cases where no callus formation is reported mostly come from very early radiographic studies on pseudofractures, particularly Milkman (1930; 1934), who characterized them by an absence of callus, even upon treatment with vitamin D therapy. However, vitamin D resistance and gastrointestinal function were never considered (Magilligan and Dulligan, 1952). It is possible that the patient Milkman saw had a genetic deficiency, but his characterization of all pseudofractures as having no callus has informed other work.

Radiographic studies that claim an absence of callus formation is characteristic of pseudofractures also do not provide any pathophysiological reason as to why a complete lack of callus mineralization would occur in the case of nutritional deficiencies.

Alternately, the discrepancy in the visibility of a callus in radiological research may be an artifact of radiographical equipment and procedure. Studies that do not detect the presence of a callus are older (Table 3). Clinical x-rays are designed to minimize exposure in living patients, resulting in lower quality images, often of lower resolution, than those that can be taken using industrial machines, which are often used in paleopathology (Buckberry and O'Connor, 2007). The older studies also used film x-rays, which may have had lower resolution than modern, digital machines, such as those used in this study (Buckberry and O'Connor, 2007). It is possible that paleopathological studies that utilise industrial radiography are better positioned to diagnose radiographic features of pseudofractures than clinical studies due to the greater dynamic range of the resultant images, but further work would be required to evaluate differences in observable features with approaches and equipment used through time.

\section{Table 3}

Radiographic studies discussing the presence of calluses in pseudofractures.

\begin{tabular}{|c|c|c|c|c|}
\hline \multirow[t]{2}{*}{ Study } & \multicolumn{3}{|c|}{ Type of Vitamin D Deficiency } & \multirow{2}{*}{$\begin{array}{l}\text { Presence of } \\
\text { Callus on } \\
\text { X-ray }\end{array}$} \\
\hline & Nutritional & Genetic & Unknown & \\
\hline Nowell et al., 1951 & $\checkmark$ & & & $\checkmark$ \\
\hline Simpson et al., 1973 & $\checkmark$ & & & $\checkmark$ \\
\hline Chadha et al., 2001 & $\checkmark$ & & & $\checkmark$ \\
\hline Lee \& Lashari, 2007 & $\checkmark$ & & & $\checkmark$ \\
\hline Edeiken \& Schneeberg, 1943 & & & $\checkmark$ & $\checkmark$ \\
\hline Milkman, 1934 & & & $\checkmark$ & $\mathrm{x}$ \\
\hline Le May \& Blunt, 1949 & & & $\checkmark$ & $\mathrm{x}$ \\
\hline Rose, 1956 & & $\checkmark$ & & $\mathrm{x}$ \\
\hline
\end{tabular}

Nutritional refers to a deficiency of vitamin D caused by lack of sunlight and adequate dietary supplementation, while genetic refers to inherited conditions. Unknown means the underlying cause was not specified or the paper was published prior to an understanding of these conditions. Callus indicates callus was reported prior to medical intervention. For types of vitamin D deficiency, $\checkmark=$ presence of a nutritional, genetic or unknown deficiency. For presence of a callus on $\mathrm{x}$-ray, $\checkmark=$ present, while $\mathrm{x}=$ absent.

\section{Chronicity of the pseudofracture}

The chronicity of a pseudofracture is another factor that affects the degree of callus formation that may be visible radiographically. Nowell et al. (1951) describe pseudofracture 
stages of development, where the appearance of a callus occurs at a later stage in development when the infraction has nearly extended across the bone. Berry et al. (2002) also note that bands of radiodensity, indicating new bone formation on x-ray, are indicative of chronicity. Figure 1 shows the development of a pseudofracture taking place over the course of six months, which corresponds with other clinical findings on the length of time required for pseudofractures to fully develop (Chalmers et al., 1967; Simpson et al., 1973). Pseudofractures without radiographically visible calluses may have occurred more recently than those with wellestablished calluses. In the case of a nutritional deficiency with multiple pseudofractures, it is likely that at least one should have a fully developed appearance (Nowell et al., 1951). Therefore, if no calluses are present radiographically, despite the presence of multiple pseudofractures, this could be an indication that the cause of the deficiency is genetic or acquired. Caution should be taken as it is not entirely implausible that calluses would have developed given more time. However, it may be possible to further test whether a deficiency is genetic by incorporating studies of interglobular dentin (D'Ortenzio et al., 2017) or, potentially, ancient DNA.
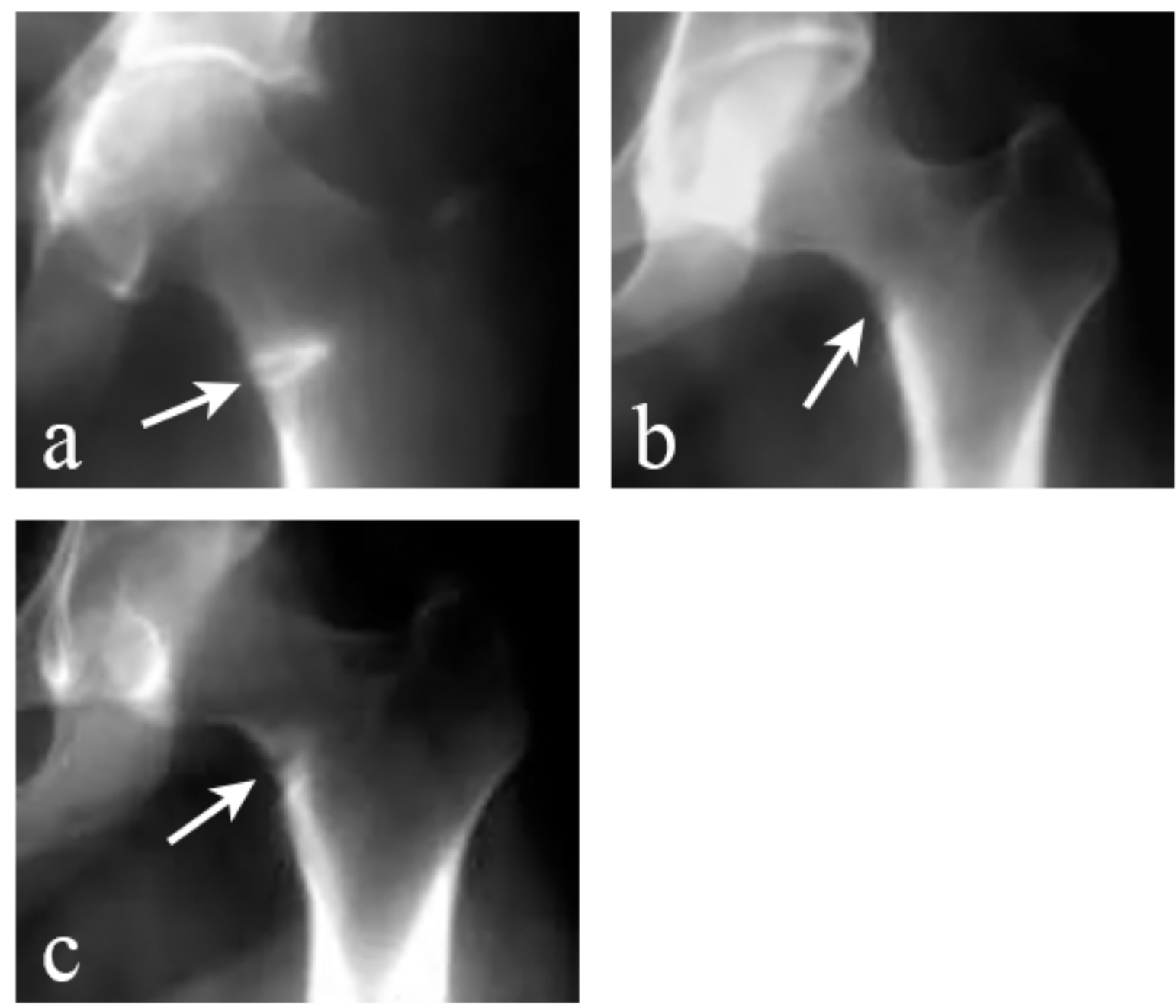
Fig. 1. Pseudofractures in a living patient with osteomalacia. (A) A pseudofracture is visible in the medial aspect of the proximal femur. Note condensation of bone along the borders of the pseudofracture, indicating chronicity. (B) No pseudofracture was initially reported in this radiograph, however, Berry et al. (2004) point out that an interruption in the continuity of the medial bone cortex of the femoral neck is just visible. (C) This shows the presence of a pseudofracture in a radiograph taken 6 months after the radiograph shown in (B), where no pseudofracture was reported. Figures reprinted from Berry et al. (2002: Fig. 4) with permission from Elsevier.

\section{Lived experience of osteomalacia in the study sample}

Having the potential to say something about the cause of a deficiency and its chronicity will provide a greater understanding of the lived experience of individuals with osteomalacia in the past. Lived experience is a term for a qualitative research approach that seeks to understand the first-hand experiences of individuals. The presence of calluses in all of the individuals in this study (see Table 2) suggests they may have had a nutritional deficiency. Preliminary research presented above suggests that the presence of a callus on $\mathrm{x}$-ray could indicate that a nutritional deficiency was present in an individual, particularly if there is additional contextual information, such as evidence of dietary inadequacy, immobilization, or cultural customs around clothing and sun exposure, which offers further support.

In the case of a single pseudofracture presenting without a callus on $\mathrm{x}$-ray, as is the case for the rib of SMB 135 (Fig. 2d), it is impossible to know whether a callus would have developed given time. However, taken with the additional pseudofractures of the scapula and clavicle, which did display fracture calluses on x-ray, and considering additional contextual information on $19^{\text {th }}$ century Birmingham (low levels of sunlight, especially in the winter, being filtered through industrial smog), it is likely that this individual had a chronic, nutritional deficiency. Each of the individuals had a mix of fracture states; some had a visible callus suggesting chronic fractures, while others may have been more recent. Figure 2 illustrates the range of developmental stages of pseudofractures seen in this study. Both PAT 7A2 54 and PAT 7A2 57 had additional healed and delayed union fractures, further suggesting a chronic vitamin D deficiency. In the clinical literature, individuals found to have pseudofractures often complain of deep muscle pain, muscle weakness, and disturbance of gait (Edeiken and Schneeberg, 1943). Nutritional deficiencies can often co-occur and vitamin D deficiency may make individuals vulnerable to other conditions (Brickley and Ives, 2008). These individuals may have continued to sustain pseudofractures, some of which may have developed into complete fractures with delayed or non-union, until adequate levels of vitamin $\mathrm{D}$ were restored. 

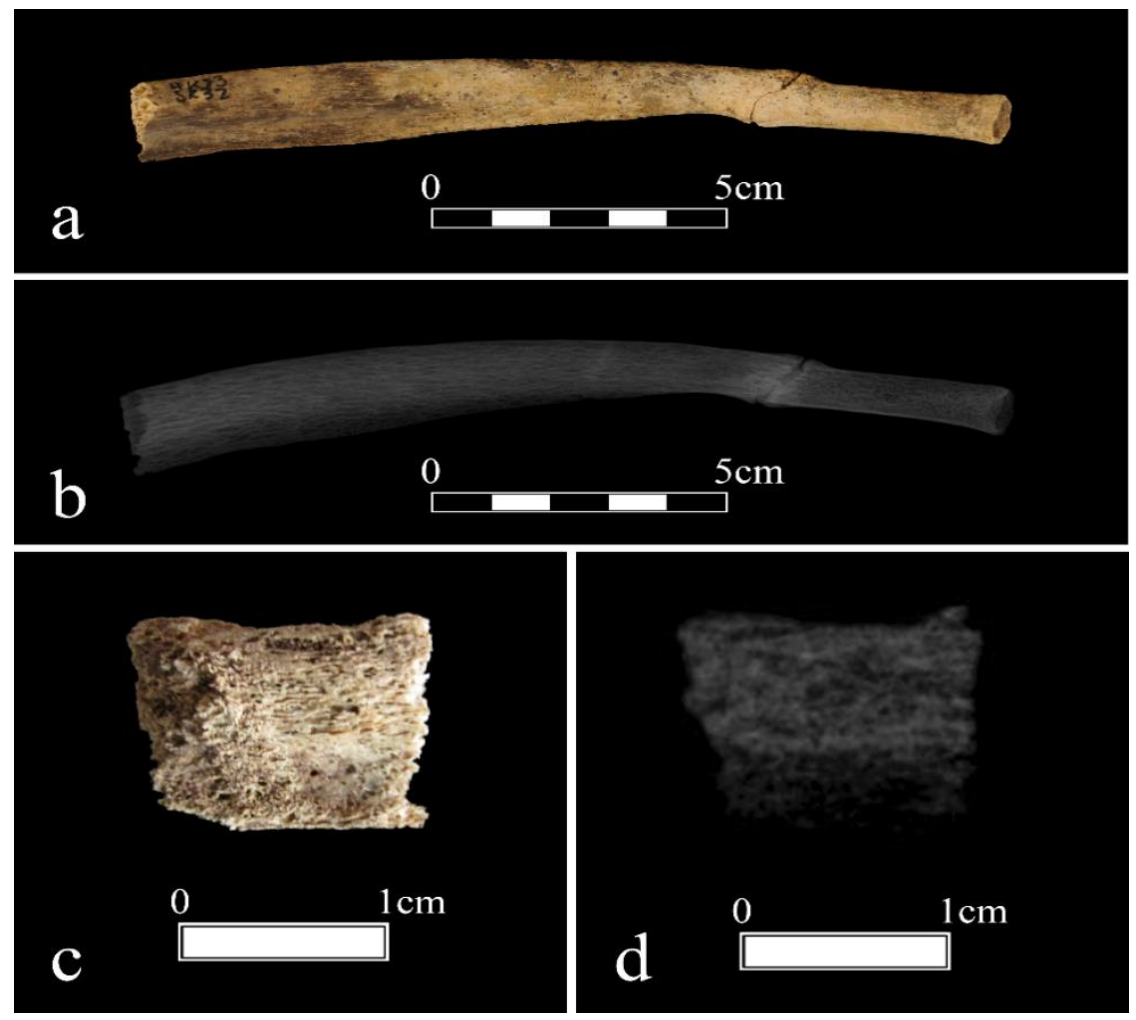

Fig. 2. Macroscopic and radiographic views of rib fractures in Hickleton 32 (a and b) and SMB 135 (c and d). a) Un-united pseudofracture with disorganized callus formation. b) Radiograph indicates a developed pseudofracture, with condensation of bone along the border of the fracture, indicating chronicity, and callus development. c) Ununited pseudofracture with disorganized, bony spicule formation. d) Radiograph indicates a less developed pseudofracture, with no difference in radiodensity at the fracture margin.

\subsection{Conclusion}

Pseudofractures should be $\mathrm{x}$-rayed to allow an assessment of callus mineralisation. Such an analysis has the potential to reveal information about the chronicity of the pseudofracture. This could also be used to identify individuals on which further tests could be conducted to investigate whether their deficiency is genetic or acquired. Caution should be taken when classifying a deficiency as nutritional. The clinical studies reviewed here suggest that it may be possible to tease apart nutritional versus genetic cases based on the level of mineralisation, but there is also disagreement within the clinical literature itself on the radiographic appearance of pseudofractures. Future research should be conducted to further test the idea that the cause of deficiency can be distinguished radiographically in skeletal samples, as evidence for this in the radiographic literature is lacking. Additional information about the lived experience of individuals with osteomalacia can be gathered through the radiographic assessment of pseudofractures and used in combination with contextual information from the site.

\subsection{Acknowledgements}

The authors would like to thank Dr. Isabel Ribot who provided access to the collections at the University of Montreal and use of the X-ray equipment. Additional thanks to Rebecca Gilmour for her help with the figures, and to the reviewers for their advice and comments. The equipment used at McMaster University was provided by the Canada Foundation for Innovation 
John R. Evans Leaders Fund (CFI-JELF), Ontario Research Fund Research Infrastructure (ORFRI) and Institutional Support from McMaster University (\#29497). Financial support was also provided by the Social Sciences and Humanities Research Council of Canada (SSHRC CGS-M). This research was undertaken, in part, thanks to funding from the Canada Research Chairs program.

\subsection{Literature Cited}

Albright, F., Reifenstein, E.C., 1948. The Parathyroid Glands and Metabolic Bone Disease. Baltimore: Williams \& Wilkins Co.

Aufranc, O.E., Jones, W.N., Harris, W.H., 1964. Multiple pseudofractures. J.A.M.A. 190, 106108.

Berry, J.L., Davies, M., Mee, A.P., 2002. Vitamin D Metabolism, Rickets, and Osteomalacia. Semin. Musculoskelet. Radiol. 6, 173-181.

Bonucci, E., Denys-Matrajt, H., Tun-Chot, S., Hioco, D.J., 1969. Bone structure in osteomalacia, with special reference to ultrastructure. J. Bone Joint Surg. 51, 511-528.

Brickley, M., Buteux, S., Adams, J., Cherrington, R., 2006. St. Martin's Uncovered: Investigations in the churchyard of St. Martin's-in-the-Bull Ring, Birmingham, 2001. Oxford: Oxbow Books.

Brickley, M., Ives, R., 2008. The Bioarchaeology of Metabolic Bone Disease. Oxford: Elsevier.

Brickley, M., Mays, S., Ives, R., 2007. An investigation of skeletal indicators of vitamin D deficiency in adults: Effective markers for interpreting past living conditions and pollution levels in $18^{\text {th }}$ and $19^{\text {th }}$ century Birmingham, England. Am. J. Phys. Anth. 132, 67-79.

Buckberry, J., O'Connor, S., 2007. Radiography in paleopathology: Where next?, in: Zakrzewski, S.R., White, W. (Eds), Proceeding of the Seventh Annual Conference of the British Association for Biological Anthropology and Osetoarchaeology. Oxford, Archaeopress, pp. 105-110.

Buikstra, J.E., Ubelaker, D.H. (Eds.), 1994. Standards for Data Collection from Human Skeletal Remains: Proceedings of a Seminar at the Field Museum of Natural History Organized by Jonathan Haas. Fayetteville: Arkansas Archaeological Survey.

Çakur, B., Sümbüllü, M.A., Dağistan, S., Durna, D., 2012. The importance of cone beam CT in the radiological detection of osteomalacia. Dentomaxillofacial Radiology. 41, 84-88.

Chalmers, J., 1967. Osteomalacia - A common disease in elderly women. J. Bone Joint Surg. 49, 403-423.

Chadha, M., Balain, B., Maini, L., Dhal, A., 2001. Spontaneous bilateral displaced femoral neck fractures in nutritional osteomalacia - a case report. Acta Orthop. Scand. 72, 94-96.

D’Ortenzio, L., Ribot, I., Kahlon, B., Bertrand, B., Bocaege, E., Raguin, E., Schattmann, A., Brickley, M., 2017. The rachitic tooth: The use of radiographs as a screening technique. Int. J. Paleopath. In press.

Edeiken, L., Schneeberg, N.G., 1943. Multiple Spontaneous Idiopathic Symmetrical Fractures. J.A.M.A. 122, 865-870.

Faibish, D., Boskey, A.L., 2005. Mineralization, in: Feldmen, D., Glorieux, F.H., Pike, J.W. (Eds), Vitamin D. London: Academic Press, pp. 477-495.

Fogelman, I., Carr, D., 1980. A comparison of bone scanning and radiology in the evaluation of patients with metabolic bone disease. Clinical Radiology. 31, 321-326.

Foster, B.L., Nociti, F.H., Somerman, M.J., 2014. The rachitic tooth. Endo. Rev. 35, 1-34.

Habener, J.F., Mahaffey, J.E., 1978. Osteomalacia and disorders of vitamin D metabolism. Ann. Rev. Med. 29, 327-342.

Holick, M.F., 2007. Medical progress: Vitamin D deficiency. N. Engl. J. Med. 357, 266-281.

Ives, R., Brickley, M., 2014. New findings in the identification of adult vitamin D deficiency 
osteomalacia: Results from a large-scale study. Int. J. Paleopath. 7, 45-56.

Keller, K.A., Barnes, P.D., 2008. Rickets vs. abuse: A national and international epidemic. Pediatr. Radiol. 38, 1210-1216.

Le May, M., Blunt, J.W., 1949. A factor in determining the location of pseudofractures in osteomalacia. J. of Clin. Invest. 28, 521-525.

Lee, C., Lashari, S., 2007. Pseudofracture of the neck of the femur secondary to osteomalacia. J. Bone Joint Surg. 89, 956-958.

Magilligan, D.J., Dulligan, P.J., 1952. Milkman's pseudofracture. J. Bone Joint Surg. 34, 170174.

Mankin, H.J., 1974. Rickets, osteomalacia, and renal osteodystrophy. J. Bone Joint Surg. 56, 101-128.

Mays, S., 2018. How should we diagnose disease in paleopathology? Some epistemological considerations. Int. J. Paleopathol. 20, 12-19.

McKenna, M.J., Heffernan, E., Hurson, C., and McKiernan, F.E., 2014. Clinician approach to diagnosis of stress fractures including biphosphonate-associated fractures. Q. J. Med. 107, 99105.

McKenna, M.J., Kleerekoper, M., Ellis, B.I., Parfitt, A.M., Frame, B., 1987. Atypical insufficiency fractures confused with Looser zones of osteomalacia. Bone. 8, 71-78.

Milkman, L., 1930. Pseudofractures (Hunger osteopathy, late rickets, osteomalacia): Report of a case. Am. J. Roent. 24, 29-37.

Milkman, L., 1934. Multiple spontaneous idiopathic symmetrical fractures. Am. J. Roent. 32, 622-634.

Nowell, S., Evans, P.R.C., Kurrein, M.B., 1951. Multiple spontaneous "Pseudofractures" of bone. Br. Med. J. 91-94.

Parfitt, A.M., 1998. Osteomalacia and related disorders, in: Avioli, L., Krane, S. (Eds), Metabolic Bone Disease and Clinically Related Disorders, Third Edition. San Diego: Academic Press, pp. 645662.

Parfitt, A.M., 2005. Vitamin D and the pathogenesis of rickets and osteomalacia, in: Feldmen, D., Glorieux, F.H., Pike, J.W. (Eds), Vitamin D. London: Academic Press, pp. 1029-1048.

Priemel, M., von Domarus, C., Klatte, T.O., Kessler, S., Schlie, J., Meier, S., Proksch, N., Pastor, F., Netter, C., Streichert, T., Puschel, K., Amling, M., 2010. Bone mineralization defects and vitamin D deficiency: Histomorphometric analysis of iliac crest bone biopsies and circulating 25Hydroxyvitamin D in 675 patients. J. Bone Miner. Res. 25, 305-312.

Reginato, A.J., Coquia, J.A., 2003. Musculoskeletal manifestations of osteomalacia and rickets. Best Pract. Res. Clin. Rheumatol. 17, 1063-1080.

Reginato, A.J., Falasca, G.F., Pappu, R., McKnight, B., Agha, A., 1999. Musculoskeletal manifestations of osteomalacia: Report of 26 cases and literature review. Semin. Arthritis Rheum. 28, 287-304.

Rose, G.A., 1956. Renal tubular osteomalacia. Br. Med. J. 2, 805-807.

Shore, R.M., Chesney, R.W., 2013. Rickets: Part II. Pediatr. Radiol. 43, 152-172.

Shore, R.M., Poznansky, A.K., 1999. Radiologic evaluation of bone mineral in children, in: Favus, M. (Ed.), Primer on the Metabolic Bone Diseases and Disorders of Mineral Metabolism Fourth Edition. Philadelphia: Lippincott William and Wilkins, pp. 119-134.

Simpson, W., Young, J.R., Clark, F., 1973. Pseudofractures resembling stress fractures in Punjabi immigrants with osteomalacia. Clin. Radiol. 24, 83-89.

Steinbach, H., Kolb, F., Gilfillan, R., 1954. A mechanism of the production of pseudofractures in osteomalacia (Milkman's syndrome). Radiology. 62, 388-395. 